\title{
Operative versus nonoperative treatment in children with painful rigid flatfoot and talocalcaneal coalition. Results from a retrospective comparative study.
}

Giovanni Luigi Di Gennaro

IRCCS Istituto Ortopedico Rizzoli

Stefano Stallone

IRCCS Istituto Ortopedico Rizzoli

Eleonora Olivotto

IRCCS Istituto Ortopedico Rizzoli

Paola Zarantonello

IRCCS Istituto Ortopedico Rizzoli

Marina Magnani

IRCCS Istituto Ortopedico Rizzoli

Tullia Tavernini

IRCCS Istituto Ortopedico Rizzoli

Stefano Stilli

IRCCS Istituto Ortopedico Rizzoli

giovanni Trisolino ( $\nabla$ giovanni.trisolino@ior.it)

IRCCS Istituto Ortopedico Rizzoli https://orcid.org/0000-0002-0361-9920

\section{Research article}

Keywords: tarsal coalition, talocalcaneal, flatfoot, child, surgical treatment, manipulation under anesthesia, allograft, arthroereisis

Posted Date: December 17th, 2019

DOI: https://doi.org/10.21203/rs.2.18844/v1

License: (c) (i) This work is licensed under a Creative Commons Attribution 4.0 International License.

Read Full License 


\section{Abstract}

Background: The management of painful rigid flatfoot (RFF) with talocalcaneal coalition (TCC) is controversial. We aimed to compare operative and nonoperative treatment in children with RFF and TCC.

Methods: We retrospectively reviewed medical records and radiographs of children with RFF and TTC treated between 2005 and 2015. The nonoperative treatment consisted of manipulation under anesthesia, cast immobilization and shoe insert after cast removal. The operative treatment consisted of combined TCC resection, graft interposition and subtalar arthroereisis.

Results: Thirty-four Children (47 feet) in the nonoperative group and twenty-one children (34 feet) in the operative group were included. No differences were found between groups, concerning baseline characteristics. The mean age at treatment was 11.8 years (9-17). The mean follow-up averaged 6.6 (312) years. There were no complications in either groups. At the latest follow-up, the AOFAS-AHS improved in both groups, although the operative group showed significantly better improvement. The operative group reported also significantly better FADI score, after adjustment for follow-up and baseline variables.

Conclusions: The operative treatment showed better results compared to the nonoperative treatment. Symptomatic RFF with TCC in children can be effectively treated in one step with resection, graft interposition and subtalar arthroereisis. Keywords: tarsal coalition, talocalcaneal; flatfoot; child; surgical treatment; manipulation under anesthesia; allograft; arthroereisis.

\section{Introduction}

The congenital tarsal coalition is a partial or complete fusion between two or more midfoot or hindfoot bones, due to abnormal formation of bone, cartilage or fibrous tissue. ${ }^{24}$

The incidence of tarsal coalition is about $1 \%$, although, being often asymptomatic, the true prevalence is around $13 \%, 26,30,31,44,46$ with a male predominance and bilaterality in $50 \%$ of cases. ${ }^{24}$ The talocalcaneal coalition (TCC) and the calcaneo-navicular coalition (CNC) are the most frequent compared to other types. ${ }^{4,45}$

Many patients with TCC typically show a rigid flatfoot (RFF) with loss of the medial arch. ${ }^{5,44}$ Pain is present in about $25 \%$ of cases; symptoms generally start in the second decade of life, when the coalition ossifies. ${ }^{5,46}$ The management of symptomatic RFF with TCC is controversial. ${ }^{29}$ Many authors agree that conservative treatment must be initially attempted, while surgery should be reserved when conservative treatment fails. ${ }^{2,12,24,28,29}$

Historically, subtalar or triple arthrodesis has been recommended for pain relief. 9,35 More recently, some authors reported good results following bar resection, possibly associated with interposition of various tissues. ${ }^{11,18,21,23,27,45,48}$ This treatment aims to relieve pain and increase subtalar motion. 
Moreover, some authors stressed the importance of the correction of the hindfoot alignment, during the management of painful RFF with TCC. ${ }^{15,16,20,36,38,48}$

The aim of this study was to compare nonoperative and operative treatment in children affected by TCC and RFF.

\section{Patients And Methods}

After institutional review board approval, a retrospective review of medical records and radiographs was conducted in patients admitted for painful RFF with TTC between 2005 and 2015 at a single tertiary referral center for pediatric orthopedics. All the patients were treated according to the surgeon's preference thus the study was not randomized. Children with painful TCC and RFF (defined "Staheli Arch Index" > 1.28 and rearfoot eversion $>10^{\circ 1,6}$ ) were enrolled. Computed Tomography (CT) was performed to confirm the diagnosis. We divided our cohort in two groups: A) nonoperative, consisting of manipulation under anesthesia and cast application (34 children; 47 feet); B) operative, consisting in TCC resection, graft interposition and subtalar arthroereisis ( 21 children; 34 feet).

We excluded from the study: children treated for idiopathic or secondary flatfoot without tarsal coalition; tarsal coalitions other than TCC; children who underwent other operations; children with incomplete documentation or lost to follow-up. A flow-chart showing the patients' selection is reported in Fig. 1.

An Italian validated version of the American Orthopaedic Foot and Ankle Society Ankle-Hindfoot Score (AOFAS-AHS) was completed at admission for each patient. ${ }^{25}$, Lateral talar-first metatarsal angle and calcaneal pitch were calculated on radiographs. On CT we assessed the heel valgus, the coalition area, the subtalar joint space narrowing (JSN) and the presence of osteoarthritis (OA) of the subtalar joint. ${ }^{8,32,48}$ The tarsal coalition was classified according to the Rozansky's classification. ${ }^{40}$

Nonoperative treatment consisted of manipulation in supination under anesthesia; then a short-leg cast in inversion was applied for 5 weeks. ${ }^{9}$ After cast removal, patients received custom shoe inserts to reduce overpronation and support plantar arch.

The operative treatment consisted of combined TCC resection, allograft interposition and correction of the hindfoot alignment by subtalar athroereisis with a nonresorbable screw (SPHERUS talar screw, Gruppo Bioimpianti® - Milan - Italy).

\section{Surgical technique}

The patient was placed in supine position, with a pneumatic torniquet on the tight. A medial incision was performed, starting from the posterior apex of the medial malleolus, continuing for $5 \mathrm{~cm}$ over the sustentaculum tali, until the posterior border of the palpable navicular bone (Fig. 2a). The tendon sheath was incised longitudinally, to expose the tibialis posterior tendon, that was retracted dorsally, while flexor hallucis longus and flexor digitorum longus tendons were retracted plantarly (Fig. 2b). The deltoid 
ligament was dissected over the bone bridge, that was exposed, identifying the talonavicular joint anteriorly and the residual talocalcaneal joint posteriorly. The bridge was excised with an osteotome, obtaining separation and complete motion of the talocalcaneal joint (Fig. 2c). A calibrated spreader was used to obtain an adequate gap for insertion of the graft (Fig. 2d). A lateral incision was performed over the sinus tarsi, identifying the lateral facet of the talus and exposing the tarsal canal. A frozen fascia lata allograft was folded in two layers before positioning (Fig. 2e). The size of the allograft was prepared according to the size of the resected area. A blunt dissection was performed to slightly dilate the tarsal canal and facilitate the graft passage. The graft was passed into the tarsal canal and the two layers of the graft were carefully placed on the bony surfaces of talus and calcaneus at the level of the coalition, mimicking the articular surfaces of the talocalcaneal joint ${ }^{13}$ (Fig. 2f). The edges of the graft were fastened to the surrounding bony or capsular structures, using suture anchors or absorbable stitches (Fig. 2 g). Using the same lateral approach, a screw housing was prepared by a straight awl, and the body of the talus was penetrated obliquely upwards. Under fluoroscopic control, a talar screw was then inserted in the housing, until the spherical head of the screw, projecting into the sinus tarsi and resting against the floor of the latter, provided the desired degree of correction (Fig. $2 \mathrm{~h}$ ). The tension of the Achilles' tendon was checked, and a percutaneus tendon lenghtening, was further performed, whenever the ankle did not achieve at least $5^{\circ}$ of dorsiflexion with the knee flexed.

A plaster cast was applied for 4 weeks. After cast removal, walking with full weight bearing was allowed as soon as pain was tolerable.

The screw was removed after two years, if the foot increased by two or more shoe sizes.

\section{Follow-up}

Patient were followed for at least three years (at least 1 year after screw removal in the operative group). Data were collected and analyzed by two independent observers. The clinical and functional outcomes were assessed by the AOFAS-AHS and the Italian validated version of the Foot and Ankle Disability Index (FADI). ${ }^{41}$ Both questionnaires were completed during the latest follow-up visit.

\section{Statistical Analysis}

Continuous data were expressed as means, whereas categorical and ordinal data were expressed as absolute values and percentages. Normality was tested using the chi-square test for categorical variables and the Kolmogorov-Smirnov test for continuous variables. Differences in baseline and outcome characteristics between groups were tested using Fisher's exact test for categorical variables and Student's t-test for paired and unpaired data (normal distribution) or Mann-Whitney U-test and Wilcoxon signed-rank test (skewed distribution) for continuous variables. Exploratory univariable analyses with general linear models were performed to identify potential associations among baseline variables and outcomes. Linear mixed effect models with patient as random effect were used, to avoid violation of the principle of independence in bilateral cases. Results were presented as crude and adjusted means with 95\% Confidence Intervals. 
Propensity analysis was used for adjustment of potential selection biases in operative decision. ${ }^{37}$ For each patient, we estimated propensity scores (PS) for receiving nonoperative or operative treatment, using a binary logistic model that included baseline variables. The balance of the PS was checked observing the overlap in the range of propensity scores across the two treatments and comparing the quintiles. T-test showed no statistically significant differences in covariate means between groups after matching. Examining treatment effects on the outcome across PS quintiles, no association was observed between the outcome and the probability of receiving either treatment, meaning that there is no evidence of unmeasured bias. PS were used to derive inverse probability of treatment weights (IPTW), with the inverse of the propensity score for the operative group and the inverse of 1 minus the propensity score for nonoperative group. Then, the IPTW were used to adjust the difference in AOFAS-AHS and FADI between groups. Statistical significance was set at $p<.05$. All analyses were performed with SPSS v. 22.0 (SPSS, Chicago, IL, USA).

\section{Results}

The study involved 55 children (35 males, 20 females; 26 bilateral cases) accounting for overall 81 feet. No differences were found between groups, concerning age at treatment, gender, bilaterality, baseline AOFAS-AHS, radiographic features (table 1).

The mean age at treatment was 11.8 years (9-17). There were no correlations between AOFA-AHS at baseline and sex, age, bilaterality, radiografic features. In all cases, the area of the coalition involved less than $50 \%$ of the subtalar joint and no radiographic OA was observed.

The mean follow-up averaged 6.6 (3-12) years and was significantly longer in the nonoperative group (7.8 versus 4.7 years; $p<0.0005)$, since the operative procedure was increasingly practiced in the latest years.

At the latest follow-up, the AOFAS-AHS significantly increased in both groups, although the operative group showed more pronunced improvements (table 2). Also the FADI score was better in the operative group, after adjustment for follow-up duration and IPTW (table 3). With the numbers available, age, gender, AOFAS-AHS at baseline and radiographic parameters did not affect the final outcome.

Postoperative radiographs were available only in 4 cases in the nonoperative group and in 13 cases in the operative group, thus the differences between preoperative and postoperative radiographic values were not evaluated.

In the nonoperative group, no complications were reported, but 6 patients ( 7 feet) were unsatisfied with the nonoperative treatment and required surgery two to four years after treatment. In the operative group, we did not report any complication related to the operation. In 4 patients ( 5 feet) a percutaneous achille's tendon lenghtening was performed during the operation, in order to achieve $5^{\circ}$ of ankle dorsiflexion.

An illustrative case is showed in figure 3.

\section{Discussion}


Currently, poor evidence supports the management of painful RFF with TCC in children. Recommended treatment includes manipulation, continuous or intermittent casting and orthosis, while surgery is generally reserved to those cases in which nonoperative treatment fails. 2,12,24,29

Concerning the nonoperative treatment, it can relieve pain and improve function in $25 \%-68 \%$ of cases. ${ }^{9}, 14,39,42,43,47$ Most authors suggested that surgery should be performed on patients whose symptoms were not relieved by conservative treatment. However, previous reports about nonoperative treatment were often weakened by limited statistical analysis or lack of essential outcome measures. We found that nonoperative management produced satisfactory outcomes (total AOFAS-AHS > 80 ) in $45 \%$ of cases and only 7 feet required surgery after nonoperative treatment. Although our results are consistent with previous studies, we believe that efforts should be done to avoid costly and time consuming nonoperative attempts, if they are destined to fail or to be unsatisfactory for the patient. A possible prognostic factor could be the level of pain at baseline as recently suggested by Birisik ${ }^{2}$; therefore, children with high level of pain could be addressed directly with operative treatment.

If surgery is considered for definitive management, the surgeon must keep in mind the goals of surgery: to eliminate pain and improve function. ${ }^{18,29}$

Currently, there is no complete agreement concerning the best surgical strategy in children with RFF and TCC. Recommended treatments include bar resection alone or combined with tissue interposition and hindfoot correction, ${ }^{12,15,18,23,32,44,47}$ isolated calcaneal osteotomy, ${ }^{29}$ subtalar fusion or triple arthrodesis; the latter being recommended for subtalar $\mathrm{OA}$, failure of previous surgeries, or large irresectable coalitions with severe heel valgus. ${ }^{9,35}$ The known poor long-term outcomes of triple arthrodesis, however, make this an undesirable option, particularly for children. ${ }^{28}$

Concerning the resection of the coalition, several authors reported favorable results in children with isolated TCC resection.

Wilde et al reported results from 17 children (20 feet) undergoing TCC resection and fat interposition. ${ }^{48}$ He found that heel valgus $>16^{\circ}$, coalition area $>50 \%$, JSN and impingement of the lateral talar process on the calcaneum were predictors of symptoms' recurrence after surgery. Gantsoudes et al. ${ }^{15}$ analyzed a cohort of 32 children (49 feet) treated with TCC resection and fat tissue interposition. They reported satisfactory results in 42 feet (84\%), but 11 feet required secondary procedures, in particular 8 corrective osteotomies to realign the hindfoot. The authors aknowledged that a valgus heel could worsen the outcome but they abitually postponed the hindfoot correction, since the use of a cast for eigth weeks could increase the likelyhood of relapse.

Mosca reported outcomes from a cohort of children who underwent isolated calcaneal osteotomy for RFF with TCC, concluding that heel valgus correction may achieve pain relief, whether or not the coalition is resected. ${ }^{29}$ 
Based on our experience, the heel valgus, whenever present, should be addressed along with the TCC, in order to avoid symptomatic recurrence and need for re-operation.

In our practice, the subtalar arthroereisis is the preferred technique to address the heel valgus in children. Currently, this technique is commonly used to address painful flexible flatfoot in children. 3,10,19,33,34 The main advantages include minimal invasiveness, short surgical time, early return to daily activities, favorable and durable results with low rate of complications. The lateral arthroereisis does not burn any bridges for future treatment modalities, making this procedure suitable for children. ${ }^{33}$ The screw arthroereisis limits the need for long period of cast immobilization. Moreover, there is initial evidence that lateral arthroereisis may offer a potentially less-invasive alternative to lateral column lengthening. ${ }^{7}$

Some brief reports and short case-series describe the association of TCC resection and hindfoot realignment in children. ${ }^{16,20}$

Giannini et al. investigated 12 children (14 feet) undergoing TCC resection and subtalar arthroereisis by bioresorbable screw, reporting improvement of the subtalar motion in 13/14 patients, complete restoration of alignment in 3 feet, partial in the remaining 11 feet and pain improvement in all cases, at a mean follow-up of 3 years. The authors demonstrated that hindfoot alignment, subtalar motion, and age at surgery were predictors of symptoms' recurrence after surgery. ${ }^{16}$ These findings were confirmed also in other studies, suggesting that, whenever indicated, this kind of surgery should be undertaken at an early age, before the arthritic changes of the subtalar joint might jeopardize the outcomes. ${ }^{36,48}$

Kernback described excellent results in 3 children with RFF and TCC, undergoing combined TCC resection and calcaneal osteotomy. ${ }^{20}$

To the best of our knowledge, we presented the largest series of RFF with TCC in children, comparing nonoperative and operative management. Nonetheless, this study has weaknesses. The retrospective design and lack of randomization introduced potential biases. In particular, the follow-up duration was different between groups and insufficient for the potential onset of subtalar OA, especially in the operative group. We performed propensity analysis and statistical adjustment to correct or mitigate biases, nonetheless the concern remains. Few postoperative radiographs were available, therefore, no conclusion could be drawn about radiographic correction, recurrence of coalition, and onset of radiographic $O A$.

The AOFAS-AHS is a clinician-based outcome measure, which lacks sufficient reliability, validity and numeric threshold for a clinically significant difference. ${ }^{22}$

To overcome this issue, we administered the FADI at the latest visit, but the lack of a preoperative patientreported measure limits any consideration about the real effectiveness of both treatments from the patient's perspective. The study compared two possible ways to manage RFF and TCC, thus it cannot completely answer to some important questions such as the role of manipulation over just immobilization, the risk-effectiveness and cost-effectiveness of the anesthesia, the effect of the 
arthroereisis over just resection and the comparison with other surgical procedures, such as osteotomies. The allograft interposition possibly reduces the rate of relapse and increases subtalar motion but increases the costs of the procedure; therefore, additional studies must be conducted to demonstrate the superiority of the allograft over autograft (fat tissue, tendon sheath), silicone or bone wax.

\section{Conclusion}

Our study describes a one-step procedure combining TCC resection, graft interposition and subtalar arthroereisis. This procedure produced better outcomes than the nonoperative treatment, increasing subtalar motion and improving foot posture in most cases. Further prospective randomized studies are needed to confirm our findings and to identify the best operative strategy in this condition.

\section{Abbreviations}

RFF

rigid flatfoot

TCC

talocalcaneal coalition

CNC

calcaneonavicular coalition

\section{Declarations}

\section{COMPETING INTERESTS}

The authors declare no conflicts of interest related to any aspects of the presented manuscript.

\section{CONTRIBUTION}

Conception and study design, analysis and data interpretation: GL Di Gennaro, S Stallone, G Trisolino. Data acquisition: P Zarantonello, M Magnani, T Tavernini. Manuscript drafting and revision: GL Di Gennaro, S Stallone, E Olivotto, S Stilli, G Trisolino. All authors read and approved the final manuscript.

\section{ACKNOWLEDGEMENT}

We thank Maria Pia Cumani for the illustrations and the production of the video describing the surgical technique. We also thank Elettra Pignotti for her support in statistical analysis. 


\section{FUNDING}

The authors received no financial support for the research, authorship, and/or publication of this article.

\section{AVAILABILITY OF DATA AND MATERIALS}

The datasets used and/or analysed during the current study are available from the corresponding author on reasonable request.

\section{ETHICS APPROVAL AND CONSENT TO PARTICIPATE}

Ethics approval was sought and obtained from the Central Emilia Wide Area Ethical Committee of the Emilia-Romagna region (CE-AVEC) (PG nr. 0000315). The study was conducted in accordance with the Helsinki declaration and all patients gave informed consent in writing to participate. Parents provided written consent for the inclusion of the patients in this study, since all the patients were minors (age less than 18) at the time of participation in the study.

\section{CONSENT FOR PUBLICATION}

Patients and parents provided written consent for the publication of their personal data in the present manuscript. The authors made any attempt to preserve patients' anonymity, by omitting unessential identifying details.

\section{References}

1.

Banwell HA, Paris ME, Mackintosh S, Williams CM. Paediatric flexible flat foot: how are we measuring it and are we getting it right? A systematic review. J Foot Ankle Res. 2018;11:21. doi:10.1186/s13047-0180264-3.

2.

Birisik F, Demirel M, Bilgili F, Salduz A, Yeldan I, Ismet Kilicoglu O. The natural course of pain in patients with symptomatic tarsal coalitions: A retrospective clinical study. Foot Ankle Surg. 2019. doi:10.1016/j.fas.2019.03.002.

3.

Caravaggi P, Lullini G, Berti L, Giannini S, Leardini A. Functional evaluation of bilateral subtalar arthroereisis for the correction of flexible flatfoot in children: 1-year follow-up. Gait Posture. 2018;64:1528. doi:10.1016/j.gaitpost.2018.06.023.

4. 
Carr JB 2nd, Yang S, Lather LA. Pediatric Pes Planus: A State-of-the-Art Review. Pediatrics. 2016;137(3):e20151230. doi:10.1542/peds.2015-1230.

5.

Cass AD, Camasta CA. A review of tarsal coalition and pes planovalgus: clinical examination, diagnostic imaging, and surgical planning. J Foot Ankle Surg. 2010;49(3):274-93. doi:10.1053/j.jfas.2010.02.003.

6.

Chang $\mathrm{CH}$, Chen $\mathrm{YC}$, Yang WT, et al. Flatfoot diagnosis by a unique bimodal distribution of footprint index in children. PLoS One. 2014;9(12):e115808. doi:10.1371/journal.pone.0115808.

7.

Chong DY, Macwilliams BA, Hennessey TA, Teske N, Stevens PM. Prospective comparison of subtalar arthroereisis with lateral column lengthening for painful flatfeet. J Pediatr Orthop B. 2015;24(4):345-53. doi:10.1097/BPB.0000000000000179.

8.

Cohen MM, Vela ND, Levine JE, Barnoy EA. Validating a new computed tomography atlas for grading ankle osteoarthritis. J Foot Ankle Surg. 2015;54(2):207-13. doi:10.1053/j.jfas.2014.06.017.

9.

Cowell HR. Talocalcaneal coalition and new causes of peroneal spastic flatfoot. Clin Orthop Relat Res. 1972;85:16-22.

10.

De Pellegrin M, Moharamzadeh D, Strobl WM, Biedermann R, Tschauner C, Wirth T. Subtalar extra-articular screw arthroereisis (SESA) for the treatment of flexible flatfoot in children. J Child Orthop. 2014;8(6):47987. doi:10.1007/s11832-014-0619-7.

11.

de Wouters S, Tran Duy K, Docquier PL. Patient-specific instruments for surgical resection of painful tarsal coalition in adolescents. Orthop Traumatol Surg Res. 2014;100(4):423-7.

doi:10.1016/j.otsr.2014.02.009.

12.

Docquier PL, Maldaque P, Bouchard M. Tarsal coalition in paediatric patients. Orthop Traumatol Surg Res. 2019;105(1S):123-31. doi:10.1016/j.otsr.2018.01.019.

13.

Docquier PL, Paul L, Mousny M, Cornu O, Delloye C. The use of allografts in paediatric orthopaedic surgery. Acta Orthop Belg. 2007;73(5):551-7.

14.

Elkus RA. Tarsal coalition in the young athlete. Am J Sports Med. 1986;14(6):477-80.

doi:10.1177/036354658601400608.

15.

Gantsoudes GD, Roocroft JH, Mubarak SJ. Treatment of talocalcaneal coalitions. J Pediatr Orthop. 2012;32(3):301-7. doi:10.1097/BPO.0b013e318247c76e.

16. 
Giannini S, Ceccarelli F, Vannini F, Baldi E. Operative treatment of flatfoot with talocalcaneal coalition. Clin Orthop Relat Res 2003(411):178-87. doi:10.1097/01.blo.0000069897.31220.7a.

17.

Gougoulias N, O'Flaherty M, Sakellariou A. Taking out the tarsal coalition was easy: but now the foot is even flatter. What now? Foot Ankle Clin. 2014;19(3):555-68. doi:10.1016/j.fcl.2014.06.011.

18.

Hubert J, Hawellek T, Beil FT, et al. Resection of Medial Talocalcaneal Coalition With Interposition of a Pediculated Flap of Tibialis Posterior Tendon Sheath. Foot Ankle Int. 2018;39(8):935-41.

doi:10.1177/1071100718768257.

19.

Jay RM, Din N. Correcting pediatric flatfoot with subtalar arthroereisis and gastrocnemius recession: a retrospective study. Foot Ankle Spec. 2013;6(2):101-7. doi:10.1177/1938640012470714.

20.

Kernbach KJ, Blitz NM, Rush SM. Bilateral single-stage middle facet talocalcaneal coalition resection combined with flatfoot reconstruction: a report of 3 cases and review of the literature. Investigations involving middle facet coalitions-part 1. J Foot Ankle Surg. 2008;47(3):180-90.

doi:10.1053/j.jfas.2008.02.005.

21.

Khoshbin A, Law PW, Caspi L, Wright JG. Long-term functional outcomes of resected tarsal coalitions. Foot Ankle Int. 2013;34(10):1370-5. doi:10.1177/1071100713489122.

22.

Kitaoka HB, Meeker JE, Phisitkul P, Adams SB Jr, Kaplan JR, Wagner E. AOFAS Position Statement Regarding Patient-Reported Outcome Measures. Foot Ankle Int. 2018;39(12):1389-93. doi:10.1177/1071100718809066.

23.

Krief E, Ferraz L, Appy-Fedida B, et al. Tarsal Coalitions: Preliminary Results After Operative Excision and Silicone Sheet Interposition in Children. J Foot Ankle Surg. 2016;55(6):1264-70. doi:10.1053/j.jfas.2015.03.009.

24.

Lawrence DA, Rolen MF, Haims AH, Zayour Z, Moukaddam HA. Tarsal Coalitions: Radiographic, CT, and MR Imaging Findings. HSS J. 2014;10(2):153-66. doi:10.1007/s11420-013-9379-z.

25.

Leigheb M, Janicka P, Andorno S, Marcuzzi A, Magnani C, Grassi F. Italian translation, cultural adaptation and validation of the "American Orthopaedic Foot and Ankle Society's (AOFAS) ankle-hindfoot scale". Acta Biomed. 2016;87(1):38-45.

26 .

Linklater J, Hayter CL, Vu D, Tse K. Anatomy of the subtalar joint and imaging of talo-calcaneal coalition. Skeletal Radiol. 2009;38(5):437-49. doi:10.1007/s00256-008-0615-4.

27. 
McCormack AP, Niki H, Kiser P, Tencer AF, Sangeorzan BJ. Two reconstructive techniques for flatfoot deformity comparing contact characteristics of the hindfoot joints. Foot Ankle Int. 1998;19(7):452-61. doi:10.1177/107110079801900706.

28.

Mosca VS. Subtalar coalition in pediatrics. Foot Ankle Clin. 2015;20(2):265-81.

doi:10.1016/j.fcl.2015.02.005.

29.

Mosca VS, Bevan WP. Talocalcaneal tarsal coalitions and the calcaneal lengthening osteotomy: the role of deformity correction. J Bone Joint Surg Am. 2012;94(17):1584-94. doi:10.2106/JBJS.K.00926. 30 .

Murphy JS, Mubarak SJ. Talocalcaneal Coalitions. Foot Ankle Clin. 2015;20(4):681-91. doi:10.1016/j.fcl.2015.07.009.

31.

Nalaboff KM, Schweitzer ME. MRI of tarsal coalition: frequency, distribution, and innovative signs. Bull NYU Hosp Jt Dis. 2008;66(1):14-21.

32.

Olney BW, Asher MA. Excision of symptomatic coalition of the middle facet of the talocalcaneal joint. J Bone Joint Surg Am. 1987;69(4):539-44.

33.

Ortiz CA, Wagner E, Wagner P. Arthroereisis: What Have We Learned? Foot Ankle Clin. 2018;23(3):415-34. doi:10.1016/j.fcl.2018.04.010.

34.

Pavone V, Costarella L, Testa G, Conte G, Riccioli M, Sessa G. Calcaneo-stop procedure in the treatment of the juvenile symptomatic flatfoot. J Foot Ankle Surg. 2013;52(4):444-7. doi:10.1053/j.jfas.2013.03.010. 35.

Peterson HA. Dowel bone graft technique for triple arthrodesis in talocalcaneal coalition-report of a case with 12-year follow-up. Foot Ankle. 1989;9(4):201-3.

36.

Philbin TM, Homan B, Hill K, Berlet G. Results of resection for middle facet tarsal coalitions in adults. Foot Ankle Spec. 2008;1(6):344-9. doi:10.1177/1938640008326235.

37.

Pirracchio R, Resche-Rigon M, Chevret S. Evaluation of the propensity score methods for estimating marginal odds ratios in case of small sample size. BMC Med Res Methodol. 2012;12:70. doi:10.1186/1471-2288-12-70.

38.

Quinn EA, Peterson KS, Hyer CF. Calcaneonavicular Coalition Resection With Pes Planovalgus Reconstruction. J Foot Ankle Surg. 2016;55(3):578-82. doi:10.1053/j.jfas.2016.01.048. 39.

Rouvreau P, Pouliquen JC, Langlais J, Glorion C, de Cerqueira Daltro G. Synostosis and tarsal coalitions in children. A study of 68 cases in 47 patients. Rev Chir Orthop Reparatrice Appar Mot. 1994;80(3):252-60. 
40.

Rozansky A, Varley E, Moor M, Wenger DR, Mubarak SJ. A radiologic classification of talocalcaneal coalitions based on 3D reconstruction. J Child Orthop. 2010;4(2):129-35. doi:10.1007/s11832-009-02243.

41.

Sartorio F, Vercelli S, Bravini E, et al. [Foot and ankle ability measure: cross-cultural translation and validation of the Italian version of the ADL module (FAAM-I/ADL)]. Med Lav. 2014;105(5):357-65. 42.

Saxena A, Erickson S. Tarsal coalitions. Activity levels with and without surgery. J Am Podiatr Med Assoc. 2003;93(4):259-63.

43.

Shirley E, Gheorghe R, Neal KM. Results of Nonoperative Treatment for Symptomatic Tarsal Coalitions. Cureus 2018;10(7):e2944. doi: 10.7759/cureus.2944.

44.

Solomon LB, Ruhli FJ, Taylor J, Ferris L, Pope R, Henneberg M. A dissection and computer tomograph study of tarsal coalitions in 100 cadaver feet. J Orthop Res. 2003;21(2):352-8.

45.

Sperl M, Saraph V, Zwick EB, Kraus T, Spendel S, Linhart WE. Preliminary report: resection and interposition of a deepithelialized skin flap graft in tarsal coalition in children. J Pediatr Orthop B. 2010;19(2):171-6. doi:10.1097/BPB.0b013e3283356256.

46.

Stormont DM, Peterson HA. The relative incidence of tarsal coalition. Clin Orthop Relat Res 1983(181):28-36.

47.

Takakura Y, Sugimoto K, Tanaka Y, Tamai S. Symptomatic talocalcaneal coalition. Its clinical significance and treatment. Clin Orthop Relat Res 1991(269):249-56.

48.

Wilde PH, Torode IP, Dickens DR, Cole WG. Resection for symptomatic talocalcaneal coalition. J Bone Joint Surg Br. 1994;76(5):797-801.

\section{Tables}




\begin{tabular}{|c|c|c|c|}
\hline [NE VARIABLE & GROUP A (nonoperative) & GROUP B (operative) & $p$-VALUE \\
\hline aildren (feet) & $34(47)$ & $21(34)$ & .07 \\
\hline male ratio & $23 / 11$ & $12 / 9$ & .35 \\
\hline ars) $[$ mean \pm SD (range)] & $11.6 \pm 2.1(9-17)$ & $12.2 \pm 1.2(10-15)$ & .07 \\
\hline -AHS pain [mean \pm SD (range)] & $28 \pm 4(20-40)$ & $28 \pm 5(20-30)$ & .71 \\
\hline- AHS function [mean \pm SD (range)] & $42 \pm 3(35-47)$ & $42 \pm 4(27-47)$ & .76 \\
\hline -AHS alignment [mean \pm SD (range) $]$ & $1 \pm 2(0-10)$ & $1 \pm 2(0-5)$ & .29 \\
\hline -AHS tot [mean \pm SD (range)] & $70 \pm 7(55-87)$ & $70 \pm 7(47-82)$ & .47 \\
\hline 3RAPHIC DATA & GROUP A (nonoperative) & GROUP B (operative) & $p$-VALUE \\
\hline $\begin{array}{l}\text { sal Pitch }\left(^{\circ}\right)[\text { mean } \pm \text { SD }(\text { range })] \\
\text { s angle }\left(^{\circ}\right)[\text { mean } \pm \mathrm{SD}(\text { range })] \\
\text { lgus }\left(^{\circ}\right)[\text { mean } \pm \mathrm{SD}(\text { range })] \\
\mathrm{m})[\text { mean } \pm \mathrm{SD}(\text { range })] \\
\text { ky classification }\end{array}$ & $\begin{array}{l}13.7 \pm 3.9(9-20) \\
12.6 \pm 4.3(8-20) \\
23.7 \pm 8.8(6.6-46.8) \\
2.8 \pm 1.0(0.6-4.8) \\
\text { I: } 13 \\
\text { II: } 9 \\
\text { III: } 12 \\
\text { IV: } 8 \\
\text { V: } 5\end{array}$ & $\begin{array}{l}14.7 \pm 3.1(11-21) \\
13.3 \pm 4.7(9-21) \\
26.4 \pm 7.7(12.8-38.5) \\
2.7 \pm 0.9(1.7-4.8) \\
\text { I: } 18 \\
\text { II: } 4 \\
\text { III: } 7 \\
\text { IV: } 4 \\
\text { V: } 1\end{array}$ & $\begin{array}{l}.48 \\
.82 \\
.37 \\
.28 \\
.19\end{array}$ \\
\hline
\end{tabular}

Table 1: Baseline demographic, clinical and radiographic data.

\begin{tabular}{|c|c|c|c|c|c|c|c|}
\hline L OUTCOME & GROU & A (nonope & ative) & GROUP I & (operative) & & $p$-VALUE \\
\hline & baseline & follow-up & $\mathrm{MD}$ & baseline & & MD & \\
\hline $\mathrm{HS}$ & $\begin{array}{l}28 \\
(26-29)\end{array}$ & $\begin{array}{l}30 * \\
(28-32)\end{array}$ & $\begin{array}{l}2 \\
(-1-5)\end{array}$ & $\begin{array}{l}28 \\
(26-30)\end{array}$ & $\begin{array}{l}37 * * \\
(34-39)\end{array}$ & $\begin{array}{l}9 \\
(6-12)\end{array}$ & .002 \\
\hline HS function & $\begin{array}{l}42 \\
(41-43)\end{array}$ & $\begin{array}{l}43^{*} \\
(41-45)\end{array}$ & $\begin{array}{l}1 \\
(-1-3)\end{array}$ & $\begin{array}{l}42 \\
(40-43)\end{array}$ & $\begin{array}{l}47 * * \\
(45-49)\end{array}$ & $\begin{array}{l}6 \\
(4-8)\end{array}$ & .04 \\
\hline HS alignment & $\begin{array}{l}1 \\
(0-2)\end{array}$ & $\begin{array}{l}5^{* *} \\
(4-6)\end{array}$ & $\begin{array}{l}4 \\
(3-6)\end{array}$ & $\begin{array}{l}1 \\
(0-2)\end{array}$ & $\begin{array}{l}10 * * \\
(9-11)\end{array}$ & $\begin{array}{l}9 \\
(7-10)\end{array}$ & .001 \\
\hline HS & $\begin{array}{l}70 \\
(68-73) \\
\end{array}$ & $\begin{array}{l}78 * * \\
(74-82)\end{array}$ & $\begin{array}{l}8 \\
(3-12)\end{array}$ & $\begin{array}{l}71 \\
(68-73)\end{array}$ & $\begin{array}{l}94 * * \\
(89-98)\end{array}$ & $\begin{array}{l}24 \\
(19-29)\end{array}$ & $<.0005$ \\
\hline
\end{tabular}

Table 2: comparison between baseline and latest follow-up AOFAS-AHS in the nonoperative and operative groups. The results are expressed as estimated means.

The estimated means were adjusted by inverse probability of treatment weights (IPTW) and follow-up duration (covariates were calculated at 6.5 years of follow-up), using the patient as random effect to avoid violation of the principle of independence in bilateral cases. 95\% confidence interval of the estimated mean is reported in brackets. 
MD = Mean Difference between baseline and latest follow-up AOFAS-AHS.

The asterisks refer to the statistical difference between baseline and follow-up values within the same group. *: difference is significant at $\mathrm{p}<.05{ }^{* *}$ : difference is significant at $\mathrm{p}<.0005$.

The P-value in the last column is referred to the statistical difference between the MD of the two groups.

\begin{tabular}{l|l|l|l|l|l|}
\hline \multirow{2}{*}{ CAL OUTCOME } & \multicolumn{2}{|c|}{ GROUP A (nonoperative) } & \multicolumn{2}{c|}{ GROUP B (operative) } & \multirow{2}{*}{$p$-VALUE } \\
\cline { 2 - 5 } tot & Crude mean & Estimated mean & Crude mean & Estimated mean & \\
\cline { 2 - 5 } pain & $83(57-100)$ & $81(78-84)$ & $92(64-100)$ & $93(87-98)$ & $<.0005$ \\
function & $87(50-100)$ & $85(82-100)$ & $94(69-100)$ & $97(92-100)$ & $<.0005$ \\
sport & $85(59-100)$ & $84(81-87)$ & $93(64-100)$ & $94(90-98)$ & .03 \\
\hline
\end{tabular}

Table 3: post-operative clinical and functional outcome measured and FADI . Group A: non-operative group. Group B (operative group). The results are expressed as crude and estimated means. The crude means are reported as mean and range. The estimated means were adjusted by inverse probability of treatment weights (IPTW) and follow-up duration (covariates were calculated at 6.5 years of follow-up), using the patient as random effect to avoid violation of the principle of independence in bilateral cases. 95\% confidence interval of the estimated mean is reported in brackets.

The P-value in the last column is referred to the statistical difference between the estimated means of the two groups.

\section{Figures}




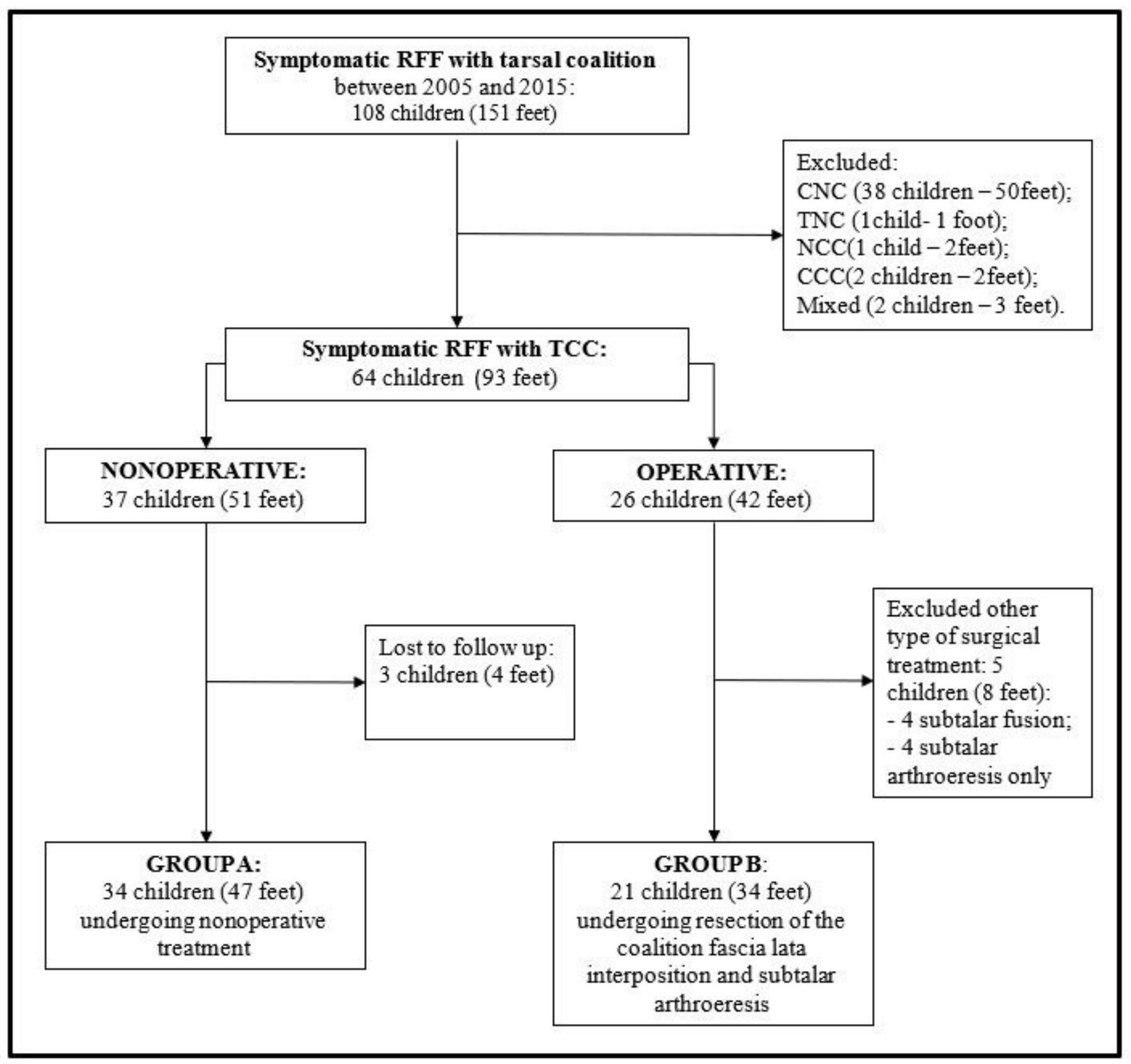

Figure 1

Flow-chart showing the patient selection criteria. List of abbreviation RFF: rigid flatfoot. TCC: talocalcaneal coalition. CNC: calcaneonavicular coalition. NCC: navicularcuneiform coalition. CCC: calcaneocuneiform coalition.

Figure 2 
Illustrations of the surgical technique step by step. a) A medial approach is performed with an incision over the sustenctaculum tali, centered to the coalition. b) The tibialis posterior tendon is retracted dorsally, while flexor hallucis longus and the flexor digitorum longus tendons are retracted plantarly, exposing the bone bridge. c) After the identification of the talonavicular joint anteriorly and the residual talocalcaneal joint posteriorly, the bridge is excised using osteotomes. d) The joint is open with a spreader, gaining the separation and complete motion of the talocalcaneal joint. e) A lateral incision is performed over the sinus tarsi, exposing the lateral facet of the talus. A frozen fascia lata allograft is folded in two layers before positioning. f) The fascia lata allograft is passed from lateral to medial into the tarsal canal and the two layers of the graft are placed covering the bony surfaces of the resected area. g) The edges of the graft are fastened with suture anchors or absorbable stitches. h) A calcaneostop screw is inserted in the talus to keep the correction.

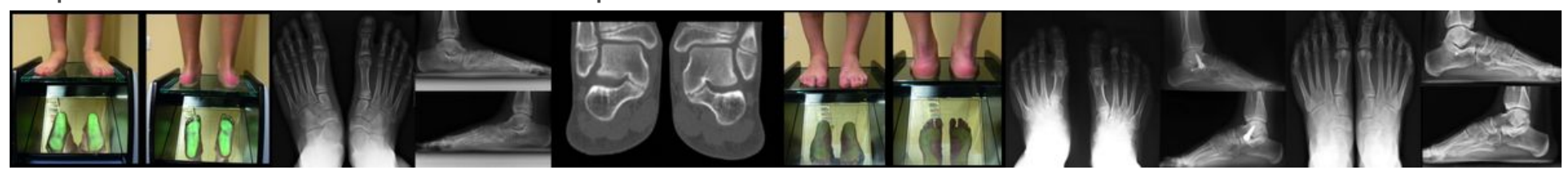

Figure 3

Clinical and radiographic features of 12 years old boy with RFF and TCC. a) Clinical aspect on podoscope. b) Antero-posterior and lateral radiographs of the same patient showing the collapse of the longitudinal arch, hindfoot valgus, and forefoot abduction. The "talar beak", evident on the neck of the talus, suggests the presence of TCC. c) Coronal CT scan of both feet showing "type I" TCC according to the Rozansky's classification. d) Post-operative clinical aspect on podoscope 1 month after surgery. e) Radiographic aspect showing the screw arthroeresis with correction of the flatfoot. f) Radiographs 6 years after screw removal, showing that the correction is maintained and the radiographic parameters are restored. 